\title{
FATORES DE ATRAÇÃO EM PARQUES TECNOLÓGICOS NA REGIÃO SUL E ESTUDO DE CASO DE IMPLANTAÇÃO DO PARQUE CIENTÍFICO E TECNOLÓGICO CHAPECÓ@
}

\author{
FACTORS OF ATTRACTION IN TECHNOLOGICAL PARKS IN THE SOUTH \\ REGION - AN IMPLEMENTATION CASE STUDY OF THE SCIENTIFIC AND \\ TECHNOLOGICAL PARKCHAPECÓ@
}

Marcelo Fabiano Costella ${ }^{1}$, Patricia Romanelli ${ }^{2}$, Claudivana Sistherenn ${ }^{2}$, Cláudio Alcides $\mathrm{Jacoski}^{2}$, Beno Nicolau Bieger ${ }^{2}$

\begin{abstract}
RESUMO
A inovação trouxe e ainda trará grandes mudanças no modo de atuar de empresas, entidades representativas, instituições de ensino e de pesquisa e organizações do setor público a partir do arranjo da tripla hélice. Esta pesquisa analisa como os parques tecnológicos em operação na região sul do Brasil, que são campos de impulsão de novas pesquisas e produtos, estão estruturados em relação a fatores locacionais, bem como a relação destes fatores na atração das empresas para se instalarem nesses empreendimentos. Na sequência dessa análise, a pesquisa pautou-se em um estudo de caso dos fatores locacionais no cenário da implantação do Parque Científico e Tecnológico Chapecó@. O resultado da análise indica que os fatores de sucesso identificados estão intimamente ligados, relacionados à localização e foco do parque tecnológico, à presença de incubadoras e aos benefícios financeiros públicos utilizados. Nota-se que, aproximadamente, $80 \%$ dos fatores locacionais avaliados foram classificados como importantes ou com importância vital para atrair empresas para o empreendimento. Em comparação com a região na qual o Parque Científico e Tecnológico Chapecó@ será inserido, os critérios avaliados se enquadram como atrativos, aumentando as chances de sucesso do empreendimento.

Palavras-chave: Parque tecnológico; Empresas Inovadoras; Geração de Conhecimento.
\end{abstract}

\footnotetext{
ABSTRACT

The innovation brought and is still bringing changes in the way of working in companies, representatives entities, learning and research institutions and organizations of the public sector through the triple helix arrangement. This research analyses how the technological parks that operate in the south of Brazil and are fields of thrust of new research and products, are structured in comparison to the local factors, as well as the relation among these factors to

${ }^{1}$ Coordenador do Programa de Pós-Graduação em Tecnologia e Gestão da Inovação. Universidade Comunitária da Região de Chapecó.

${ }^{2}$ Universidade Comunitária da Região de Chapecó.
} 
attract companies to certain areas and subsequently settle these enterprises. The research was based on a case study of local factors in the implementation scenario for the Scientific and Technological Park Chapecó@. The analysis result indicates that the success factors identified are closely interconnected, related to the location and focus of the technological park, the presence of incubators and public financial benefits used. It has been noticed that approximately $80 \%$ of the evaluated locational factors were ranked as important or vital to attract companies to the venture importance. Compared to the region in which the Science and Technological Park Chapecó@ will be inserted, the criteria evaluated were classified as attractive, increasing the chances of the enterprise success.

Keywords: Technological Park; Innovative Companies; Knowledge Generation.

\section{INTRODUÇÃo}

O mercado globalizado e de competição intensiva nos quais países e empresas estão inseridos demandam uma busca constante por inovação. Em um contexto de mercados amplamente globalizados, as empresas se deparam com uma acirrada competição, o que faz crescer a demanda por produtos e serviços inovadores que dependem da utilização de alto grau de conhecimento em seu desenvolvimento (FIGLIOLI, 2007).

Entre os habitats de estímulo à inovação estão os chamados Parques Tecnológicos. É característico que esses parques tecnológicos se instalem perto de centros de conhecimento, como universidades e centros de pesquisa, pois a concepção destes habitats é pautada na teoria da tríplice hélice.

A tríplice hélice tem como ponto de partida os mesmos três segmentos do Triângulo de Sábato, porém sai da rigidez do triângulo para a dinâmica da hélice, dando mobilidade aos três elementos. No mesmo segmento cada hélice tem vida, características, normas, configurações próprias, porém com uma área de sobreposição em que os três segmentos atuam em conjunto em um único espaço, em processo de fusão, sem perda de suas características básicas (ETZKOWITZ; LEYDESDORFF, 1997).

Esse novo modelo vincula as instituições governamentais, as empresas e universidades a ações de processos inovadores, no qual os recursos necessários à operacionalização da rede são fornecidos a partir das condições locais. Por sua vez, a abordagem interativa passa a interferir na organização institucional de cada uma delas (ETZKOWITZ; LEYDESDORFF, 1997). 
O Brasil vem nos últimos anos almejando um maior desenvolvimento na área de inovação, buscando se inserir como país atuante nesta atual sociedade do conhecimento, fomentando o desenvolvimento de Parques Tecnológicos por todas as regiões do país.

Em virtude da necessidade de se estabelecer parâmetros que atendam ao crescente desenvolvimento do país como um todo e, principalmente, da Região Sul do Brasil, buscou-se uma avaliação dos fatores locacionais dos Parques Tecnológicos implantados nessa região e, a partir desse primeiro objetivo, estabelecer uma análise de um Parque em implantação - o Parque Científico e Tecnológico Chapecó@.

\section{FUNDAMENTOS CONCEITUAIS}

\subsection{Inovação}

Hitt et al. (2002) defendem a ideia de que a inovação impulsiona o sucesso competitivo das empresas, não somente com a criação de novos produtos, mas também através de mudanças na sua estrutura organizacional.

Os primeiros estudos a abordar a inovação no processo empreendedor foram de Schumpeter (1982), ao tratar da "destruição criadora", onde o empreendedor destrói a ordem econômica existente com a introdução de algo novo.

As necessidades e desejos dos consumidores são a fonte lógica para buscar ideias de novos produtos. Muitas das melhores ideias surgem quando se pede aos consumidores para descreverem seus problemas em relação aos produtos atuais (KOTLER, 2000).

A percepção das empresas em relação à inserção da inovação como fator de aumento da competitividade vem crescendo ano após ano, pois a demanda pela geração de conhecimento e aplicação do mesmo na indústria para criação de novos produtos aumenta gradativamente (SOLY et al., 2012).

Indicadores da capacidade de inovação de um país podem ser observados através de investimentos em ciência e tecnologia (C\&T), pesquisa e desenvolvimento (P\&D), publicações e número de patentes. Nos últimos anos um conjunto de estratégias e mecanismos vem estimulando as empresas, entre eles: “concessão de incentivos físcais, as subvenções econômicas destinadas ao custeio de projetos de pesquisa e desenvolvimento de inovação e outros instrumentos de financiamento a esses projetos" (ROCHA, 2011).

Segundo Rocha (2011), com o objetivo de levantar informações e indicadores sobre o processo de inovação das empresas, realiza-se a Pesquisa de Inovação Tecnológica 
(PINTEC), pelo Instituto Brasileiro e Geografia e Estatística (IBGE), em parceria com o Ministério da Ciência e Tecnologia (MCT) e a Financiadora de Estudos e Projetos (FINEP).

\subsection{Conceitos e características dos parques tecnológicos}

A Internacional Association of Science Park (IASP, 2012, p. 1) define parque tecnológico como "organização administrada por profissionais especializados, cujo principal objetivo é aumentar a riqueza de sua comunidade por meio da promoção da cultura de inovação e da competitividade de suas empresas associadas e instituições baseadas em conhecimento".

Neste sentido, a entidade indica que os parques são ambientes criados de forma organizada, com serviços de valor agregado, espaços de infraestrutura física de alta qualidade, com o objetivo de gerar riqueza para a região em que estão inseridos. Desse modo, o papel do parque é gerenciar o fluxo de conhecimento e tecnologia entre universidades, instituições de pesquisa e desenvolvimento, empresas e mercados, atuando como ponte, uma vez que o conhecimento passível de ser utilizado pelas empresas é produzido em diversos locais, sendo que as universidades são as maiores responsáveis pela geração do saber e pela realização do conhecimento (IASP, 2012).

Já no Brasil, a entidade que integra os parques tecnológicos e incubadoras (Associação Nacional de Entidades Promotoras de Empreendimentos Inovadores - ANPROTEC), define parque tecnológico como um:

(a) complexo industrial de base científico-tecnológica, de caráter formal, concentrado e cooperativo, que agrega empresas cuja produção se baseia em pesquisa tecnológica desenvolvida em centros de P\&D [Pesquisa e Desenvolvimento] vinculados ao Parque; (b) empreendimento promotor da cultura da inovação, da competitividade, do aumento da capacitação empresarial fundamentado na transferência do conhecimento e tecnologia, com o objetivo de incrementar a produção de riqueza (ANPROTEC, 2008, p. 80).

Considerando que nas universidades e centros de pesquisa há pessoas com conhecimento em pesquisa e que realizam novas descobertas, porém falta-lhes o conhecimento de mercado, a proximidade e a interação com essas instituições que proporcionam o fortalecimento dos parques. Neste sentido, os parques tecnológicos são considerados como instrumentos capazes de realizar essa interação entre a pesquisa acadêmica e o mercado de trabalho (STEINER; CASSIM; ROBAZZI, 2008).

A criação de um parque tecnológico demanda um plano de negócio rigoroso e detalhado, tendo em vista que se destinam a promover o surgimento e crescimento de 
empresas inovadoras, a partir da articulação dos atores do sistema de inovação, gerando mãode-obra e empregos mais qualificados, com melhores rendimentos. Além da necessidade de infraestrutura compatível com a região em que está inserido, o parque oferece "apoio ao desenvolvimento sustentável” em concordância com o plano diretor da cidade em que está instalado e promove a difusão do conhecimento por possuir estrutura de gestão formal ou informal (ZOUAIN; PLONSKI, 2006).

Em levantamento realizado, foi constatado que o Brasil possui 74 parques tecnológicos espalhados por todo seu território. A Região Sul se destaca, pois concentra o segundo maior número de parques no país, sendo 10 em operação, 6 em implantação e 7 em projeto (ANPROTEC, 2008).

Em Santa Catarina, existem alguns parques tecnológicos em operação e outros em fase de desenvolvimento. Os parques mais antigos em operação são o Sapiens Parque e o Parque Tecnológico Alfa (Parqtec Alfa), localizados em Florianópolis. Já os parques que estão em fase de implantação são o Parque InovaParq de Joinville e o IParque de Criciúma, projetos que começaram juntamente com o Chapecó@. O Orion Parque Tecnológico, localizado em Lages, está em fase de desenvolvimento, com investimento público já realizado para sua construção.

Cada parque necessita desenvolver um projeto de Ciência e Tecnologia (C\&T) específico, que detalhe seu perfil e as áreas onde pretende se especializar. Este projeto deve detalhar ainda a infraestrutura e os serviços necessários que possam atrair empresas de base tecnológica para o parque (Agência Brasileira de Promoção de Exportação e Investimentos APEX, 2011).

De acordo com Zouian e Plonski (2006), os parques tecnológicos devem ser construídos em locais com infraestrutura suficiente para oferecer atrativos às empresas que se instalarão. Entre os pontos mais relevantes, destacam-se: as instalações, recursos disponíveis, proximidade de centros urbanos, bem como o contato acadêmico com o mercado, possibilitando o desenvolvimento desse vínculo e proporcionando uma maior qualificação profissional.

De acordo com Figlioli (2007), os parques devem oferecer infraestrutura básica para que as empresas e instituições e/ou centros de pesquisa se instalem (estrutura, saneamento básico e urbanístico, facilidade de acessos, transportes, comunicação e segurança), uma vez que algumas universidades já abrigam incubadoras e centros de pesquisa. 


\subsection{Fatores de atratividade das empresas}

Ferguson e Olofsson (2004) consideram que a Empresa de Base Tecnológica (EBT) é um "[...] empreendimento que fundamenta sua atividade produtiva no desenvolvimento de novos produtos ou processos, baseado na aplicação sistemática de conhecimentos científicos e tecnológicos e utilização de técnicas avançadas ou pioneiras". Esta definiçãa sugere que, a partir de pesquisas científicas e tecnológicas direcionadas ao desenvolvimento de produtos, as EBTs promovem a inovação ao mercado.

Algumas atratividades locais devem ser consideradas para que a empresa e seus vários setores, como escritório, centro de P\&D, setor de vendas, áreas de testes, treinamento, enfim, podem ser instalados em locais diferentes e, o que pode ser atrativo para certo setor, pode não ser para outro do mesmo segmento.

Para Gonçalves (2002, p. 23), as empresas transnacionais (TNCs), caracterizadas pelo seu grande porte, são as principais agentes na internacionalização da produção, respondendo pela "quase totalidade dos fluxos de investimento externo direto". As empresas multinacionais podem ser consideradas mais de âmbito regional, exercendo papel ativo nos lugares em que são instaladas. De acordo com o mesmo autor, a maioria dos países que são escolhidos pelas empresas transnacionais e multinacionais são aqueles em que estão se desenvolvendo e não propriamente os que já estão desenvolvidos.

Assim, Gonçalves (2002, p. 61) apresenta os fatores locacionais de algumas empresas transnacionais como sendo "a existência de amplas fontes de matéria-prima e reduzidos custos de mão-de-obra". A capacidade de desenvolvimento tecnológico e mercadológico, a estabilidade na economia (realizada de forma a analisar o histórico) e o estímulo à diminuição das taxas de importação e exportação regionais ou nacionais também são fatores que, aliados, determinam a localização de uma empresa.

As empresas procuram por mercados consumidores aos quais se familiarizam, observando também a cultura, sociedade, língua e história. Outros fatores como acesso à tecnologia, baixo custo de mão-de-obra e obtenção de matéria prima com facilidade, foram citados como elementos relevantes na escolha da localização.

Algumas empresas ressaltam que, quanto maior a necessidade da existência de atividades tecnológicas, maior será a busca por localidades onde já haja uma tendência a geração do conhecimento e desenvolvimento tecnológico, preferencialmente próximo a universidades e centros de pesquisa (GONÇALVES, 2002). 
Muitos são os fatores locacionais relacionados à pesquisa e desenvolvimento, como: os custos de investimento (profissionais técnicos, equipamentos e instalações), custos de transferência (transferências de informações, tanto internas quanto externas), custos organizacionais (construção ou ampliação) e qualidade dos recursos de entrada (nível de habilidade dos profissionais e tipo/formato do laboratório).

Dentre os principais fatores de atratividade encontra-se a questão financeira, caracterizada por meio de incentivos fiscais ou fomento/financiamento dos parques tecnológicos. Os principais mecanismos públicos utilizados no financiamento de parques tecnológicos foram condensados na tabela 01 , levando em consideração suas fases de desenvolvimento, sendo elas: planejamento, implantação e operacionalização.

Tabela 01. Mecanismos de apoio por fase de desenvolvimento do parque tecnológico.

\begin{tabular}{|c|c|c|c|}
\hline & Planejamento & Implantação & Operacionalização \\
\hline Atividades & $\begin{array}{c}\text { Planejamento, } \\
\text { concepção, estudos } \\
\text { de viabilidade e } \\
\text { estruturação do } \\
\text { parque tecnológico. }\end{array}$ & $\begin{array}{l}\text { Criação da } \\
\text { infraestrutura básica e } \\
\text { ocupação das } \\
\text { edificações de uso } \\
\text { coletivo do parque } \\
\text { tecnológico. }\end{array}$ & $\begin{array}{l}\text { Ocupação do parque tecnológico } \\
\text { pelas EBTs e centros de pesquisa de } \\
\text { grandes empresas, gestão do } \\
\text { empreendimento e oferta de serviços. }\end{array}$ \\
\hline Incentivos Fiscais & Não se aplica. & $\begin{array}{l}\text { Para determinadas } \\
\text { situações, há a } \\
\text { redução ou isenção } \\
\text { dos tributos como o } \\
\text { ICMS, IPTU e ITBI e } \\
\text { a isenção de taxas, por } \\
\text { um período } \\
\text { determinado. }\end{array}$ & $\begin{array}{l}\text { Para situações, há a redução ou } \\
\text { isenção de tributos como o ICMS, } \\
\text { ISS, IPTU e ISSQN e a isenção de } \\
\text { taxas, por um período. Micro e } \\
\text { pequenas empresas tem redução à } \\
\text { zero de alíquotas de tributos como } \\
\text { IPI, COFINS e PIS/PASEP. }\end{array}$ \\
\hline $\begin{array}{l}\text { Fomento e/ou } \\
\text { Financiamentos }\end{array}$ & $\begin{array}{l}\text { Disponibilização de } \\
\text { financiamento não } \\
\text { reembolsável, como } \\
\text { o PNI, } \\
\text { operacionalizado } \\
\text { pela FINEP. }\end{array}$ & $\begin{array}{l}\text { Disponibilização de } \\
\text { financiamento } \\
\text { reembolsável, como o } \\
\text { Capital Inovador do } \\
\text { BNDES. }\end{array}$ & $\begin{array}{l}\text { Disponibilização de financiamentos } \\
\text { não reembolsáveis e reembolsáveis, } \\
\text { sendo os principais: Subvenção } \\
\text { Econômica e Inova Brasil, } \\
\text { operacionalizados pela FINEP; e } \\
\text { Funtec, Inovação Tecnológica, } \\
\text { Capital Inovador, Inovação } \\
\text { Produção, entre outros promovidos } \\
\text { pelo BNDES. }\end{array}$ \\
\hline
\end{tabular}

Fonte: SOLY et al., 2012. 


\section{PROCEDIMENTOS METODOLÓGICOS}

\subsection{Fatores de atração em parques tecnológicos na Região Sul}

\subsubsection{Amostra}

Para compor a amostra foram selecionados todos os parques tecnológicos em operação no sul do Brasil há pelo menos dois anos, totalizando nove parques tecnológicos (Tabela 02), de modo que não foram considerados parques em projeto e em implantação.

Tabela 02. Parques Tecnológicos em operação no sul do Brasil.

\begin{tabular}{c|c}
\hline \multirow{4}{*}{ Estado } & Parques Tecnológicos \\
\hline \multirow{4}{*}{ Rio Grande do Sul } & Parque Científico e Tecnológico da PUCRS - Tecnopuc \\
\cline { 2 - 2 } & Parque Tecnológico São Leopoldo -Tecnosinos \\
\cline { 2 - 2 } Santa Catarina & Parque Tecnológico do Vale dos Sinos - Valetec \\
\cline { 2 - 2 } & Sapiens Parque - Florianópolis \\
\hline \multirow{3}{*}{ Paraná } & Parque Tecnológico Alfa (PARQTEC ALFA) \\
\cline { 2 - 2 } & Programa Curitiba Tecnoparque \\
\cline { 2 - 2 } & Parque Tecnológico de Pato Branco (PTPB) \\
\cline { 2 - 2 } & Parque Tecnológico Agroindustrial do Oeste (PTAO)
\end{tabular}

Fonte: Adaptado de ANPROTEC, 2008.

\subsubsection{Seleção dos critérios comparativos e obtenção dos dados}

Por meio da análise de um estudo bibliográfico aprofundado referente aos parques tecnológicos, foram selecionados alguns critérios, adaptados dos estudos de Barquete (2002) e Manella (2009). Desses estudos foram extraídos a totalidade de 47 critérios, o qual o grupo de trabalho do Parque Tecnológico composto por 8 especialistas (mestres e doutores) da área de tecnologia, considerou um número excessivo. Deste modo foi realizado um grupo focado e selecionados 35 critérios considerados mais relevantes, sendo que estes foram divididos em 7 grupos, quais sejam:

- Acesso a incentivos fiscais e financeiros, subdividido em: incentivos públicos (Federal ou Estadual); benefícios públicos para aquisição de terrenos; fundos governamentais de apoio às empresas; 
- Qualidade de vida (o que se encontra perto dos mesmos), subdividido em: hotéis, bares e restaurantes; centros esportivos e culturais; áreas verdes e de convívio; instituições de educação (creches, escolas); áreas residenciais; sistema de transporte; áreas comerciais, shoppings, empresas de serviço;

- Infraestrutura tecnológica e de conhecimento, subdividido em: proximidade e relação com universidades; bibliotecas; laboratórios de P\&D; centros tecnológicos e institutos de P\&D; incubadoras; escritórios/serviços de transferência de tecnologia;

- Infraestrutura de comunicação e telecomunicação, subdividido em: eletrônica e multimídia; internet; telefonia; centros de conferência; videoconferência; salas de reuniões e eventos;

- Infraestrutura urbana, subdividido em: água e esgoto; ruas pavimentadas; coleta de lixo; proximidade a bancos; proximidade a estradas e rodovias; proximidade a portos e aeroportos (dentro de um raio de $45 \mathrm{~km}$ );

- $\quad$ Perfil industrial da região, subdividido em: proximidades a centros urbanos; empresas inovadoras com produtos e serviços de valor agregado; mão de obra qualificada;

- Serviços oferecidos pelo parque, subdividido em: informação sobre consultoria/ fomento a $\mathrm{P} \& \mathrm{D}$; comercialização do produto (marketing, divulgação); serviços jurídicos.

Os dados foram obtidos por meio de pesquisas em sites, portais eletrônicos, livros, informações por e-mail com as áreas administrativas dos parques, folhetos, artigos, jornais, revistas, enfim, uma gama de materiais para que o entendimento do funcionamento de cada parque tecnológico fosse o mais claro possível.

\subsubsection{Análise dos resultados}

A partir de uma tabela comparativa, na qual os critérios foram analisados por grupos, uma escala de importância foi desenvolvida, com o intuito de ressaltar quais são os fatores de atratividade que os parques tecnológicos ofertam com maior frequência às empresas.

Para cada grupo foi desenvolvido um gráfico para estabelecer melhor entendimento, sendo que as barras representam a porcentagem de parques tecnológicos que ofertam determinado critério para que as empresas se instalem. Assim, criou-se uma escala em nível de importância para as porcentagens, na qual os fatores de atratividade foram separados por grau de importância: 
- De 0 a 20\%: Grau 1 - Importância desconhecida ou sem importância;

- $\quad$ De 21 a 40\%: Grau 2 - Pouco Importante;

- $\quad$ De 41 a 60\%: Grau 3 - Importância relativa;

- $\quad$ De 61 a 80\%: Grau 4 - Importante;

- De 81 a 100\%: Grau 5 - Importância vital ou muito importante.

\subsection{Estudo de caso no projeto do Parque Científico e Tecnológico Chapecó@}

A partir da identificação dos fatores críticos para o sucesso considerados relevantes na implantação de parques tecnológicos procurou-se cruzar esses fatores com o projeto de implantação do Parque Científico e Tecnológico Chapecó@ .

O projeto do Parque Científico e Tecnológico Chapecó@ assemelha-se ao modelo norte americano de parques tecnológicos, caracterizado por áreas de pequena e média extensão, onde os projetos serão desenvolvidos com a participação da Unochapecó (Universidade Comunitária da Região de Chapecó), juntamente ao auxilio de organizações públicas (Estado de Santa Catarina e Prefeitura Municipal de Chapecó) e iniciativa privada.

A instalação do Parque em Chapecó será em uma área de terra estimada em torno de $10.000 \mathrm{~m}^{2}$, onde a intenção é concentrar no mesmo local, além das atividades universitárias, os institutos de pesquisas, as micro, pequenas, médias e grandes empresas que permitam a consolidação de uma visão empreendedora ligada à ciência, tecnologia, treinamentos, profissionalização e inovação.

Em relação análise dos resultados, após à análise dos critérios por grupos, foi realizada uma análise mais aprofundada item a item para os que receberam atribuição de graus 4 e 5 , considerados importantes e com importância vital, respectivamente, objetivando uma comparação com o atual estágio de implantação do Parque Científico e Tecnológico Chapecó@.

\section{ANÁLISE E DISCUSSÃO DOS RESULTADOS}

\subsection{Parques Tecnológicos em operação}

A Tabela 3 apresenta o cruzamento dos 7 grupos e 35 critérios selecionados para o estudo com os parques tecnológicos em operação na Região Sul do Brasil. 
Tabela 03. Critérios comparativos entre os parques tecnológicos.

Acesso a incentivos fiscais e financeiros

Qualidade de vida (proximidade a)

Infraestru-tura Tecnológica e de conheci-mento

Infraestru-tura de comunica-ção e telecomu-nicação

Infraestru-tura urbana

Perfil industrial da região pelo parque

Incentivos Públicos

(Federal ou Estadual)

Benefícios públicos para aquisição de terrenos

Fundos Governamentais de apoio as empresas

Hotéis, bares e restaurantes Sistema de transporte

Áreas verdes e de convívio Centros esportivos e culturais

Áreas comerciais, shoppings, empresas de serviço

Instituições de educação (creches, escolas)

Áreas residenciais
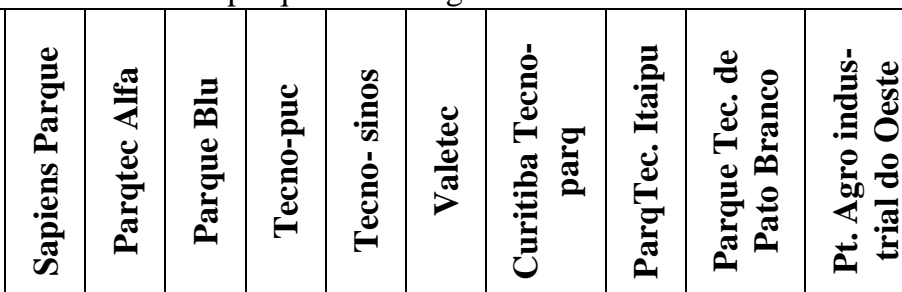

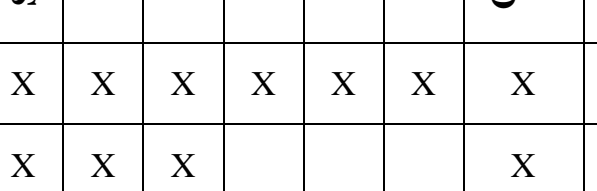

$x$

\begin{tabular}{l|l|l}
$\mathrm{X}$ & $\mathrm{X}$ & $\mathrm{X}$
\end{tabular}

\begin{tabular}{l|l|l|} 
& $\mathrm{X}$ & $\mathrm{X}$ \\
\hline
\end{tabular}
universidades Bibliotecas Incubadoras

Laboratórios de P\&D

Centros tecnológicos e Institutos de P\&D

Escritórios/serviços de transferência de tecnologia Eletrônica e multimídia

\begin{tabular}{l|l|l|l|l|l}
$\mathrm{X}$ & $\mathrm{X}$ & & $\mathrm{X}$ & $\mathrm{X}$ & $\mathrm{X}$ \\
\hline
\end{tabular}

$\mathrm{X}$

\begin{tabular}{|l|l|l|}
\hline $\mathrm{X}$ & $\mathrm{X}$ \\
\hline $\mathrm{X}$ & $\mathrm{X}$ & $\mathrm{X}$
\end{tabular}

\begin{tabular}{|c|c|c|c|c|c|c|c|c|c}
$\mathrm{X}$ & $\mathrm{X}$ & $\mathrm{X}$ & $\mathrm{X}$ & $\mathrm{X}$ & $\mathrm{X}$ & $\mathrm{X}$ & $\mathrm{X}$ & $\mathrm{X}$ & $\mathrm{X}$ \\
$\mathrm{X}$ & $\mathrm{X}$ & $\mathrm{X}$ & $\mathrm{X}$ & $\mathrm{X}$ & $\mathrm{X}$ & $\mathrm{X}$ & $\mathrm{X}$ & $\mathrm{X}$ & $\mathrm{X}$ \\
$\mathrm{X}$ & $\mathrm{X}$ & $\mathrm{X}$ & $\mathrm{X}$ & $\mathrm{X}$ & & $\mathrm{X}$ & $\mathrm{X}$ & & $\mathrm{X}$ \\
$\mathrm{X}$ & $\mathrm{X}$ & $\mathrm{X}$ & $\mathrm{X}$ & & $\mathrm{X}$ & & $\mathrm{X}$ & &
\end{tabular}

\begin{tabular}{|l|l|l|l|l|l|l|l}
$\mathrm{X}$ & $\mathrm{X}$ & $\mathrm{X}$ & $\mathrm{X}$ & & $\mathrm{X}$ & & $\mathrm{X}$ \\
\hline
\end{tabular}




\begin{tabular}{|c|c|c|c|c|c|c|c|c|c|c|c|}
\hline \multirow[t]{4}{*}{ Item } & & 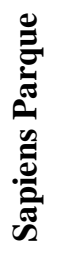 & 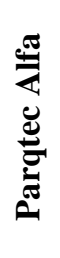 & 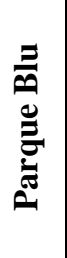 & 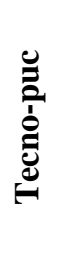 & 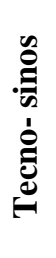 & 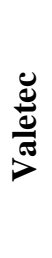 & 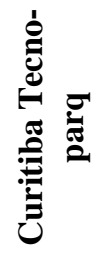 & 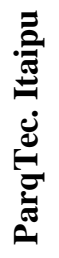 & 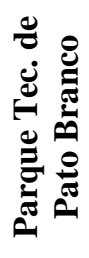 & 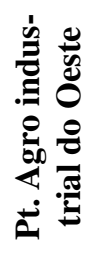 \\
\hline & divulgação) & & & & & & & & & & \\
\hline & Serviços jurídicos & & $\mathrm{X}$ & $\mathrm{X}$ & $\mathrm{X}$ & $\mathrm{X}$ & $\mathrm{X}$ & & $\mathrm{X}$ & & $\mathrm{X}$ \\
\hline & $\begin{array}{c}\text { Informação sobre } \\
\text { consultoria/fomento a P\&D }\end{array}$ & $\mathrm{X}$ & & & $X$ & $X$ & & & $X$ & & $\mathrm{X}$ \\
\hline
\end{tabular}

Fonte: Elaboração dos autores.

$\mathrm{Na}$ sequência os dados foram analisados grupo a grupo. Para o grupo Acesso a incentivos fiscais e financeiros (figura 01), os critérios avaliados foram considerados com grau 4 e grau 5. O item relacionado a incentivos públicos (federais ou estaduais) ocorreu em todos os parques tecnológicos em estudo. Já os critérios de fundos governamentais de apoio às empresas e benefícios públicos para aquisição de terrenos ocorreram em $70 \%$ dos parques.

Figura 01. Gráfico do grupo Acesso a incentivos fiscais e financeiros.

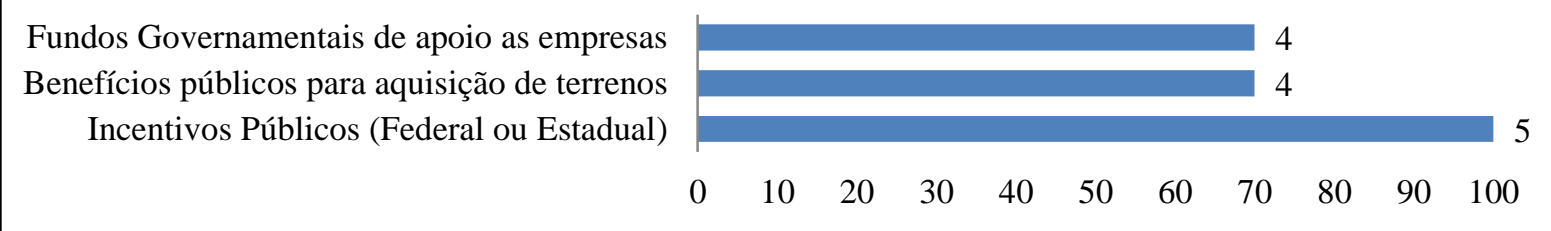

Fonte: Elaboração dos autores.

Em relação ao grupo Qualidade de vida, apresentado na figura 02, os critérios foram avaliados considerando-se a infraestrutura próxima aos centros de pesquisa, variando entre o grau 2 até o grau 5 na escala de importância. Considerados como muito importantes na escala foram avaliados os critérios de sistema de transporte e hotéis, bares e restaurantes $(100 \%$ dos parques). Avaliado com grau 4 na escala, as áreas verdes e de convívio são ofertadas por $80 \%$ dos parques tecnológicos (PqTs). Os critérios áreas comerciais, shoppings e empresas de serviço (ofertados por $50 \%$ dos PqTs) e Centros esportivos e culturais (ofertados por $60 \%$ dos PqTs) foram avaliados com grau 3 (relativamente importante). Por fim, os critérios pouco importantes, áreas residenciais e instituições de educação (creches, escolas), ocorreram em apenas $40 \%$ dos parques. 
Figura 02. Gráfico do grupo Qualidade de vida.

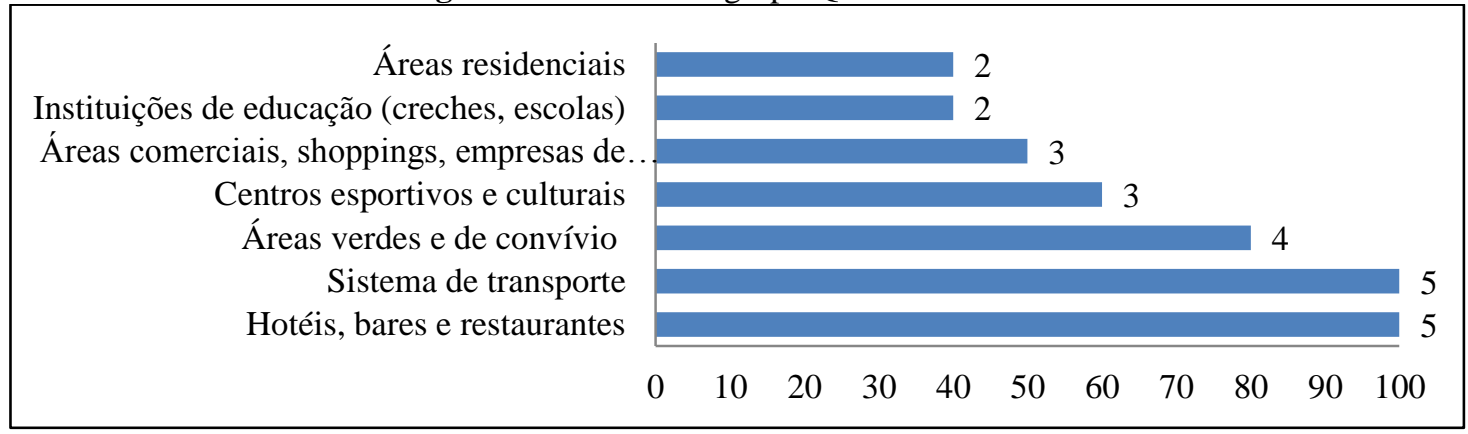

Fonte: Elaboração dos autores.

Para o grupo Infraestrutura tecnológica e de conhecimento (figura 03), dos seis critérios avaliados, quatro foram considerados muito importantes: incubadoras, bibliotecas, proximidade e relação com universidades (100\% dos PqTs), já os laboratórios de P\&D foram encontrados em 90\% dos PqTs. O item Centros Tecnológicos e Institutos de P\&D foi classificado como grau 4, sendo ofertado por $70 \%$ dos PqTs. O elemento Escritórios/Serviços de transferência de tecnologia foi classificado com importância relativa, com grau 3, ofertado por $50 \%$ dos PqTs. Nenhum item foi considerado pouco importante ou sem importância.

Figura 03. Gráfico do grupo Infraestrutura tecnológica e de conhecimento.

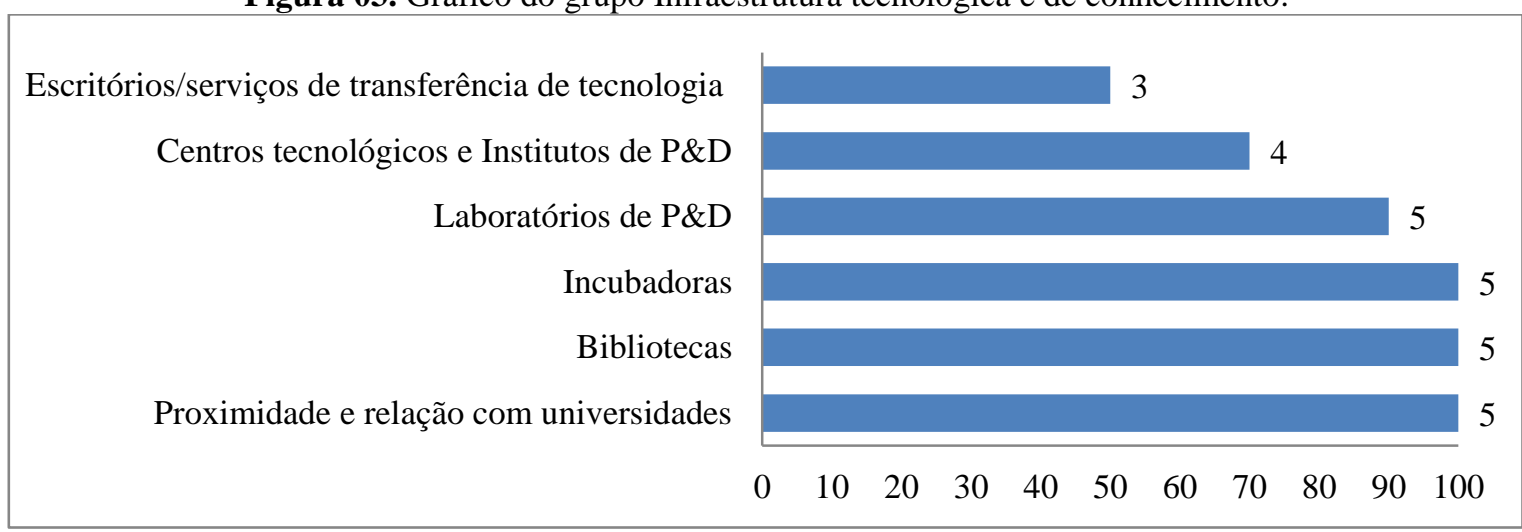

Fonte: Elaboração dos autores.

Para o grupo Infraestrutura de comunicação e telecomunicação, apresentado na figura 04,dos seis critérios avaliados, apenas o item videoconferência foi ofertado por $40 \%$ dos parques tecnológicos em operação, classificado no grau 2, com pouca importância. Os cinco ítens restantes foram classificados como muito importantes (grau 5), sendo disponibilizados em todos os parques em estudo, sendo eles: sala de reuniões e eventos, centros de conferência, telefonia, internet e eletrônica e multimídia. 
Figura 04. Gráfico do grupo Infraestrutura de comunicação e telecomunicação.

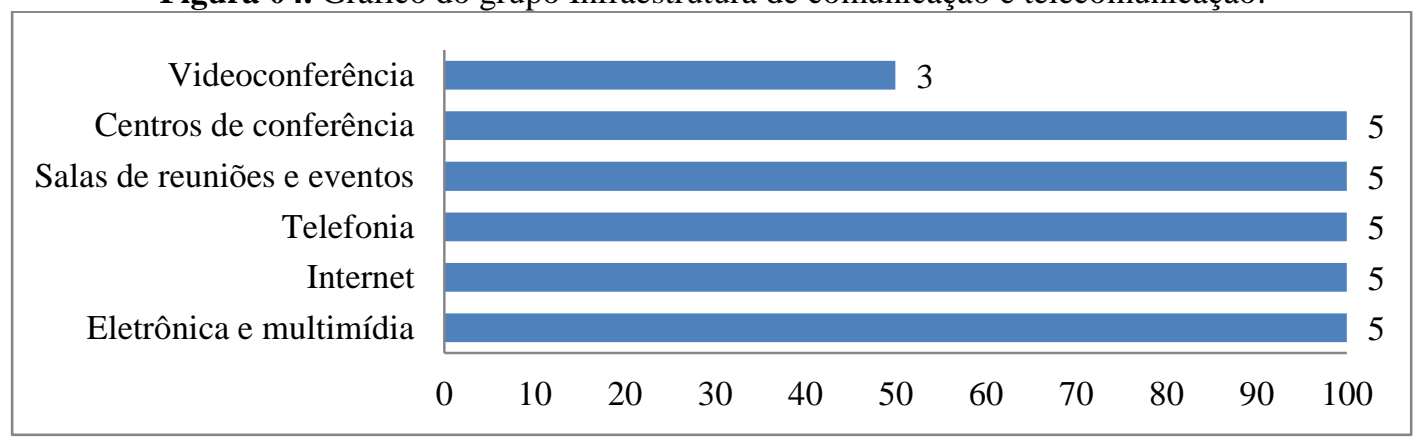

Fonte: Elaboração dos autores.

Para o grupo Infraestrutura urbana, entre os seis itens avaliados, quatro são classificados como muito importantes, com grau 5, ocorreram em 100\% dos PqTs, sendo proximidades de estradas e rodovias, coleta de lixo, ruas pavimentadas e água e esgoto. Os itens proximidade a bancos e proximidade a portos e aeroportos foram classificados como importante (grau 4), e ocorreram em $80 \%$ e $70 \%$ dos PqTs, respectivamente.

Figura 05. Gráfico do grupo Infraestrutura urbana.

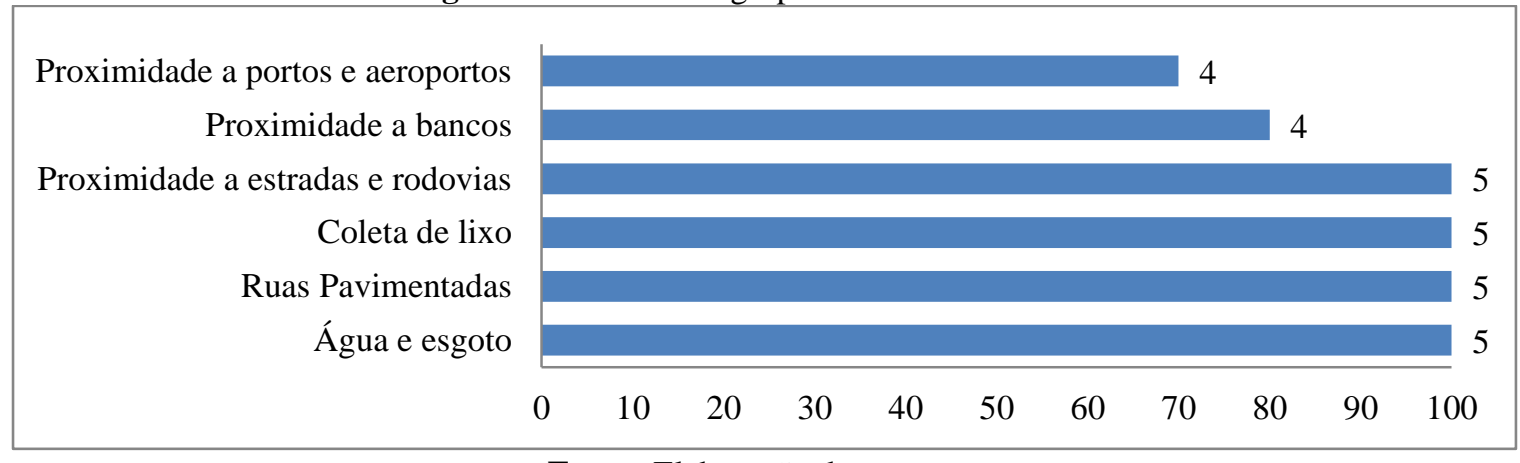

Fonte: Elaboração dos autores.

Para o grupo Perfil industrial da região, dois itens avaliados são ofertados por todos os PqTs: mão-de-obra qualificada e empresas inovadoras com produtos e serviços de valor agregado. O item proximidade a centros urbanos ocorreu em $90 \%$ dos PqTs. Todos os itens apresentados nesse grupo, de acordo com a figura 06, foram classificados com grau 5, avaliados com importância vitalícia para a empresas. 
Figura 06. Gráfico do grupo Perfil industrial da região.

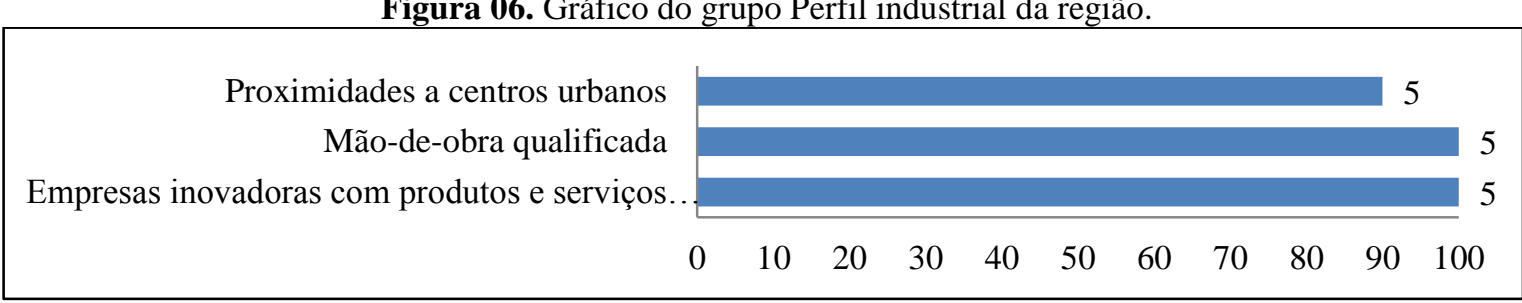

Fonte: Elaboração dos autores.

Por fim, os Serviços oferecidos pelo Parque (figura 07), apresenta um item classificado com grau 5 e ofertado por todos os PqTs às empresas: comercialização do produto (marketing, divulgação). O item serviços jurídicos classifica-se como importante na escala (grau 4), sendo oferecido por $70 \%$ dos PqTs e o elemento informação sobre consultoria/fomento à P\&D classificado como grau 3 (indiferente), ofertado em apenas 50\% dos PqTs as empresas.

Figura 07. Gráfico do grupo Serviços oferecidos pelo Parque.

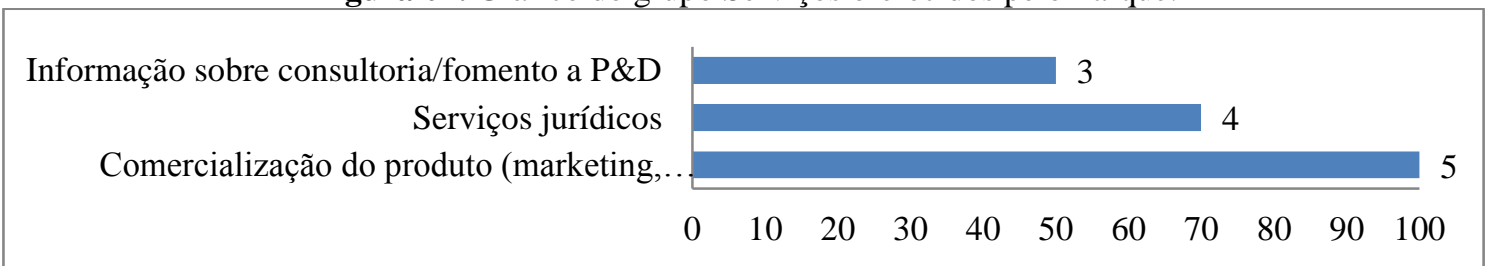

Fonte: Elaboração dos autores.

Submetendo os critérios a uma análise geral observa-se que:

- $\quad 58,8 \%$ dos critérios apresentados estão classificados como grau 5 (muito importante),

- $\quad 20,6 \%$ classificam-se como grau 4 (importante);

- $\quad 11,8 \%$ classificam-se como grau 3 (importância relativa);

- $\quad 8,8 \%$ classificam-se como grau 2 (pouco importante) na escala.

Dentre os 34 critérios selecionados, 18 itens (52\%) ocorreram em todos os parques tecnológicos estudados, sendo eles: a) Incentivos Públicos (Federal ou Estadual); b) Hotéis, bares e restaurantes; c) Sistema de transporte; d) Proximidade e relação com universidades; e) Bibliotecas; f) Incubadoras; g) Eletrônica e multimídia; h) Internet; i) Telefonia; j) Centros de conferência; k) Salas de reuniões e eventos; l) Água e esgoto; m) Ruas Pavimentadas; n) Coleta de lixo; o) Proximidade a estradas e rodovias; p) Empresas inovadoras com produtos e serviços de valor agregado; q) Mão-de-obra qualificada; r) Comercialização do produto (marketing, divulgação). 
Também foi possível observar que, em nenhum dos parques tecnológicos os fatores de atratividade para a respectiva instalação de empresas, encaixaram-se no grau 1 da escala. Assim, conclui-se que os critérios estabelecidos para o estudo foram de grande importância, conforme definido por grupo focado para tal fim.

Em relação ao critério 'localização do parque tecnológico', os que obtiveram maior sucesso foram aqueles que escolheram uma área propicia a investimentos em inovação. Observou-se que, quanto maior a proximidade dos centros urbanos, maior o desenvolvimento do mesmo, sendo que uma infraestrutura de qualidade, com hotéis, bancos, empresas de serviços, ruas pavimentadas, redes de comunicação, internet, se tornam atrativos para a instalação das empresas. Lembrando que, em relação ao terreno escolhido para implantação do parque, o mesmo deve ser planejado para que as instalações possam ser ampliadas, pressupondo o desenvolvimento do mesmo.

Observou-se que a totalidade dos parques científicos e tecnológicos utilizou 'benefícios públicos', sejam eles federais, estaduais ou municipais para sua instalação. Esses benefícios, na maioria das vezes, constituem-se na doação de terreno pela prefeitura, na fase de implantação do projeto, concessão de incentivos fiscais, subsídio econômico destinado ao custeio de projetos de pesquisa e desenvolvimento de inovação e outros instrumentos de financiamento a esses projetos. Iniciativas públicas sejam elas de forma direta, ou através de fundações e agências de fomento são fatores decisivos para fazer com que o projeto de implantação saia do papel.

Outro fator de sucesso é em relação ao 'foco do parque'. Como foram analisados anteriormente, os parques buscam instalações próximas a centros urbanos propícios ao desenvolvimento tecnológico, assim, a maioria desses centros se localiza em regiões polos que possuem setores definidos em desenvolvimento e com potencial.

As 'incubadoras' tem papel fundamental para o sucesso do parque tecnológico. Nelas, micro e pequenas empresas com potencial tem a oportunidade de crescer, através de um ambiente propício ao desenvolvimento, que conta com assessoria empresarial, contábil, financeira e jurídica, que provoca a diminuição de custos. As incubadoras surgiram como estratégia de desenvolvimento do país, pois incentivam o empreendedorismo, a criação de empregos e a qualificação da mão-de-obra.

Apesar de alguns dos fatores serem considerados de grau 4 e 5 na escala, informações disponibilizadas pelas administrações dos parques, salientam que as empresas instaladas não 
utilizam todos esses recursos. Um exemplo disso, segundo as administrações dos PqTs, é a baixa utilização dos centros de conferência.

\subsection{Parque Científico e Tecnológico Chapecó@}

A avaliação dos critérios 4 e 5 discutidos anteriormente para o projeto do Parque Científico e Tecnológico Chapecó@ estão apresentados na Tabela 04.

Tabela 04. Critérios positivos e negativos do Parque Científico e Tecnológico Chapecó@ .

\begin{tabular}{|c|c|}
\hline Avaliação & Critérios \\
\hline \multirow{12}{*}{ Positivos } & $\begin{array}{l}\text { Proximidade e relação com universidades que inclui } \\
\text { biblioteca e Incubadoras }\end{array}$ \\
\hline & Proximidades a portos e aeroportos \\
\hline & Água e esgoto \\
\hline & Coleta de lixo \\
\hline & Ruas pavimentadas \\
\hline & Proximidade a estradas e rodovias \\
\hline & Incentivos Públicos (Federal ou Estadual) \\
\hline & Benefícios públicos para aquisição de terrenos \\
\hline & Áreas verdes e de convívio \\
\hline & Internet e Telefonia \\
\hline & $\begin{array}{l}\text { Parcerias com instituições de ensino e pesquisa, } \\
\text { grandes empresas e governo }\end{array}$ \\
\hline & $\begin{array}{l}\text { Eletrônica e multimídia, Internet, Telefonia, Salas de } \\
\text { reuniões e eventos, Centros de conferência }\end{array}$ \\
\hline \multirow{10}{*}{$\begin{array}{l}\text { Necessitam de } \\
\text { melhoria }\end{array}$} & Hotéis, bares e restaurantes \\
\hline & Fundos Governamentais de apoio às empresas \\
\hline & $\begin{array}{l}\text { Proximidade a bancos } \\
\end{array}$ \\
\hline & $\begin{array}{c}\text { Empresas inovadoras com produtos e serviços de valor } \\
\text { agregado e mão-de-obra qualificada }\end{array}$ \\
\hline & $\begin{array}{c}\text { Laboratórios de P\&D e Centros tecnológicos e } \\
\text { Institutos de P\&D }\end{array}$ \\
\hline & Comercialização do produto (marketing, divulgação) \\
\hline & Serviços jurídicos \\
\hline & Sistema de transporte \\
\hline & Mão-de-obra qualificada \\
\hline & Transferência de tecnologia \\
\hline
\end{tabular}

Fonte: Elaboração dos autores.

Em relação aos incentivos públicos, a Parque está sendo construído com recursos do Governo do Estado de Santa Catarina em terreno da Prefeitura Municipal de Chapecó, o qual foi doado pela Unochapecó. Já os fundos governamentais de apoio às empresas passam por um período de incerteza e necessitam de maior aporte de recursos.

Analisando o critério Proximidade e relação com universidades, como o parque científico e tecnológico será construído nas imediações da universidade (Unochapecó), atende 
a um dos critérios decisivos para atração de empresas para o mesmo, pois a presença de universidade e centros de pesquisa é determinante para o sucesso do empreendimento. Além disso, essa universidade conta com uma ampla biblioteca e incubadora tecnológica. Um critério considerado muito importante e que foi ofertado por todos os parques em estudo foi em relação às Incubadoras. A Unochapecó já conta com duas incubadoras implantadas e mais três em implantação, nos municípios de Saudades/SDR, Maravilha, Palmitos e Seara, como incentivo à inovação. $\mathrm{O}$ fomento a micro e pequenas empresas com potencial para geração de conhecimento inovador é essencial para o sucesso do parque.

Um ponto que pode ser considerado positivo é a proximidade a aeroportos. Este critério se encaixa no grau 4 da escala e considerado importante, o qual pode ser utilizado a favor na mobilidade. Em comparação aos critérios água e esgoto, coleta de lixo e ruas pavimentadas, a região em que o parque será estruturado já está loteada, com grande ascensão residencial e nas imediações também está estabelecida a universidade.

Proximidade a estradas e rodovias seria um fator de atratividade para o parque a ser implantado, sendo que estaria no sentido da Rodovia BR-283 e não muito distante de estradas que dão acesso a outras rodovias, como a Avenida Leopoldo Sander, que esta ligada a BR 282. Esse acesso foi totalmente reformulado com oito pistas, visando melhorar a mobilidade e o grande fluxo de veículos e mercadorias que entram e saem do município.

Outros fatores de atratividade como eletrônica e multimídia, internet, telefonia, salas de reuniões e eventos, centros de conferência, considerados como infraestrutura básica de comunicação e telecomunicação estão previstos no projeto do Parque e são considerados básicos.

O critério que trata de hotéis, bares e restaurantes foi avaliado com importância vital, porém comparando-o com a região na qual será implementado o parque Chapecó@, não atende ao critério, pois está estruturado longe do centro urbano, em uma região que abrange o bairro Efapi. Porém já se observa mudanças neste item visto que um hotel está sendo projetado para ser instalado nesta proximidade.

O critério sistema de transporte, como um fator de infraestrutura básica, é disponibilizado e tende a ser satisfatório para a população local, devido ao grande número de pessoas que dependem desse sistema para mobilidade. Como a implantação do parque tecnológico será longe do centro urbano da cidade, é fundamental que haja um bom sistema de transportes. 
Quanto ao critério de mão-de-obra qualificada, o qual é decisivo para as empresas na decisão de se instalar ou não nos parques observa-se que esse item é um dos fatores negativos da região, necessitando esforços para reverter esse quadro. Nesse ponto também não se encontram ainda empresas inovadoras com produtos e serviços de valor agregado visto que o parque ainda não está concluído. Entretanto, é um ponto vital para o desenvolvimento e manutenção do Parque Chapecó@. Outro ponto que deverá ser viabilizado somente após a implantação é a comercialização do produto (marketing, divulgação) e os serviços jurídicos.

A partir dessa análise é possível afirmar que, em comparação com a região na qual o Parque Científico e Tecnológico Chapecó@ será inserido, os critérios avaliados se enquadram como atrativos, aumentando as chances de sucesso do empreendimento.

\section{CONSIDERAÇÕES FINAIS}

No presente trabalho, motivado pela busca de respostas relacionadas ao problema de pesquisa, observou-se que ainda há muitas lacunas a serem preenchidas, tratando-se do assunto ciência, tecnologia e inovação. Assim, para buscar essas respostas, sendo que o despertar para a busca pela inovação ocorreu há pouco tempo, o estudo propôs-se a analisar e investigar o surgimento dos parques tecnológicos, enfatizando os fatores locacionais atrativos nos parques em operação nos estados de Santa Catarina, Paraná e Rio Grande do Sul com posterior análise dos critérios para implantação do Parque Científico e Tecnológico Chapecó@. Observou-se que definir uma estrutura de serviços de apoio necessária para aperfeiçoar a relação empresa-universidade-centros de pesquisa é fundamental para que o parque se desenvolva, obtendo êxito. Parâmetros devem ser estabelecidos ainda na fase de implantação do parque, considerando a região na qual o parque será implantado, onde que a economia baseia-se na agroindústria e os investimentos em tecnologia iniciaram-se nesse setor.

Observa-se que outros dados são compatíveis com a literatura, sendo que as empresas que se instalaram nos parques tecnológicos em operação estudados o fazem em busca de serviços de informação, consultoria, fomento à $P \& D$ e consideram importante a disponibilidade de mão de obra qualificada de nível superior e de empresas inovadoras que produzem serviços tecnológicos de alto valor agregado.

Considerando que os parques científicos e tecnológicos foram criados com o objetivo de promover a cultura da inovação, com base na transferência do conhecimento, observou-se 
que as empresas demonstram pouco interesse pela infraestrutura tecnológica oferecida as mesmas, refletindo os baixos investimentos realizados ao longo dos anos no país.

De mesmo modo, os parques devem reunir em seu espaço físico um suporte à interação e integração entre empresas, universidades e governo, de modo que empresas de base tecnológica optem pela sua instalação nesses ambientes de inovação, aumentando assim, o bem estar da comunidade onde estão inseridos.

Apesar dos objetivos terem sido alcançados, é importante lembrar que a amostra analisada é restrita aos parques tecnológicos em operação nos estados do Paraná, Santa Catarina e Rio Grande do Sul e os resultados podem ser diferenciados em outras regiões.

\section{REFERÊNCIAS}

ASSOCIAÇÃO NACIONAL DE ENTIDADES PROMOTORAS DE EMPREENDIMENTO INOVADORES - ANPROTEC. Portfólio de Parques Tecnológicos no Brasil. Versão de Trabalho. 2008. Disponível em: http://www.anprotec.org.br/ArquivosDin/portfolio_completo _resol_media_pdf_28.pdf>. Acesso em: 07 de out. de 2012.

\section{AGENCIA BRASILEIRA DE PROMOÇÃO DE EXPORTAÇÃO E INVESTIMENTOS -} APEX. Parques Tecnológicos. São Paulo, 2011. Disponível em: <http://www.apexbrasil.com.br/portal/publicacao/engine.wsp?tmp.area=673>. Acesso em: 24 de abr. de 2012.

BARQUETE, S.. Fatores de localização de incubadoras de empreendimentos de alta tecnologia. ERA - Revista de Administração de Empresas, São Paulo, v. 42, n. 3, p. 101-113, jul./set. 2002. Disponível em: <http://www.scielo.br/pdf/rae/v42n3/v42n3 a09.pdf>. Acesso em: 21 de out. de 2012.

ETZKOWITZ, H.; LEYDESDORFF, L. Universities en the global knowledge economy: a Triple Helix do University-Industry-Government relation. Londos: Cassel, 1997.

FERGUSON, R.; OLOFSSON, C. Science Parks and the development of NTBFs - Location, survival and growth. Journal of Technology Transfer, v. 29, p. 5-17, 2004.

FIGLIOLI, A. Perspectivas de financiamento de parques tecnológicos: um estudo comparativo. Dissertação (Mestrado) - Faculdade de Economia, Administração e Contabilidade de Ribeirão Preto, 2007. Disponível em: <www.teses.usp.br/teses/disponiveis/96/96132/tde.../AlineFiglioli.pdf>. Acesso em: 05 de out. de 2012.

GIL, A. C. Como elaborar projetos de pesquisa. 4. ed. São Paulo: Atlas, 2002.

GONÇALVES, A. Parques tecnológicos: a experiência brasileira. ANPROTEC: 2002. Disponível em: <http://www.anprotec.org.br/publicação.php?idpublicacao=169>. Acesso em: 11 de Outubro de 2012. 
INTERNATIONAL ASSOCIATION OF SCIENCE PARKS AND AREAS OF INNOVATION - IASP. Definitions and Statistics, 2012. Disponível em: <http://www.iasp.ws/publico/index.jsp?enl=2>. Acesso em: 25 de Set. de 2012.

HITT, M. A.; IRELAND, R. D.; HOSKISSON, R. E. Administração estratégica. São Paulo: Pioneira Thomson Learning, 2002.

KOTLER, P. Administração de marketing: análise, planejamento, implementação e controle. 10. ed. São Paulo: Prentice-Hall, 2000.

MANELLA, B. F. P. Fatores de atratividade de empresas inovadoras para Parques Tecnológicos. 2009. 194 p. Dissertação (Mestrado em Administração de Organizações) - Ribeirão Preto, 2009.

ROCHA, M. C. A eficiência dos incentivos fiscais à inovação tecnológica. Radar Inovação, INVENTTA: 2011. Disponível em <http://inventta.net/wpcontent/uploads/2011/06/A-eficiencia-dos-incentivos-fiscais-a-inovacao.pdf $>$. Acesso em: 22 de jan. de 2013.

SCHUMPETER, J. A. Teoria do Desenvolvimento Econômico. São Paulo: Abril, 1982.

SOLY, B.; ROCHA, M.C.; LOURES, M.; AZEVEDO, P.; BICALHO, T.; BOHNENBERGER, $\mathrm{V}$. Os desafios de obter recursos financeiros para o planejamento, implantação e operacionalização de parques tecnológicos. INVENTTA: 2012. Disponível em: <http://inventta.net/wpcontent/uploads/2012/04/recursos-financeiros-parques-tecnologicos.pdf $>$. Acesso em: 10 de fev. de 2013.

STEINER, J.; CASSIM, M.; ROBAZZI, A. Parques Tecnológicos: ambientes de inovação. Instituto de Estudos Avançados de São Paulo, 2008.

ZOUAIN, D. M.; PLONSKI, G. A. Parques Tecnológicos: Planejamento e Gestão. Brasília: ANPROTEC: SEBRAE, p. 140. 2006. 